\title{
Smart Maintenance Solutions for Automated Mining Machinery
}

\author{
Seyed Hadi Hoseinie, Behzad Ghodrati, Diego Galar
}

\begin{abstract}
Automation is known as one of the most powerful tools for enhancing the mine productivity and safety. Automated mining machineries are so complex and capital intensive assets which need comprehensive maintenance, support and logistic planning to be able to meet their desired production goals. There are several technical, operational and safety challenges in the maintenance of this kind of machinery which force the mining companies to take the advanced solutions for increasing the maintenance quality and reducing the downtimes as much as possible. In this paper firstly the various automation modes of mining machinery are reviewed briefly. Thereafter, regarding to literature review and some field observation, three maintenance challenges are presented and discussed: safety of maintenance crew, maintenance big data and asset integration problems in mine automation systems. Considering the operational difficulties and safety issues the intelligent Reliability Centered Maintenance (iRCM) and eMaintenance as two advanced applicable methods are recommended for maintenance improvement in automated mining machinery.
\end{abstract}

Keywords - mining, automation, maintenance, reliability centered maintenance, eMaintenance

\section{Introduction}

Machinery as a key element of mine operation plays a critical role in productivity and production effectiveness. Technology progress in mining machinery is a long way that has been passed so far and is still on going with implementing the advanced technologies such as automation.

Since 1980s the concomitant demands for more raw minerals and higher safety levels have forced mining companies to think about changing their operation methods along with their machinery. This resulted in the creation of the automated mining. Automation is one of the ways that provides revolutionary improvements in not only mining methods and machinery but also in the operational safety. Mine automation covers everything involved when we try to replace human senses and intelligence with machines, including sensor technology, communication network and devices.

Autonomous mining is an umbrella term that refers to two types of activities. The first deals with data gathering, processes and decision making; the second deals with applying the decisions via robotic technology to mining vehicles and equipment. Getting more automated operation makes the mining systems more complex and capital intensive. The complexity affects the all operation aspects specially the maintenance, support and logistics as well.

Seyed Hadi Hoseinie, Behzad Ghodrati, Diego Galar

Division of Operation and Maintenance Engineering, Luleå University of Technology

Sweden
In the rest of the paper, firstly various automation modes of mining machinery are briefly reviewed and different elements of maintenance management system in mining are discussed. Then, the main operational difficulties and challenges in maintenance of automated machinery are presented. At the end, smart solutions for maintenance improvement in automated mining operation are studied and reviewed.

\section{Automation modes of mining machinery}

The mining operation of the future is likely to be a bit eerie, combining driverless trucks, drills and haulage trains with plant controllers monitoring operations remotely from central control stations kilometers away. Automated mine equipment comes in four forms: remote control, teleoperation, semi-automation and full automation $[1,2]$.

Remote control mining machinery usually refers to mining machinery controlled with a handheld remote control. An operator stands in the line-of-sight and uses remote control to perform the normal vehicle functions. Tele-operated mining machinery refers to mining machines controlled by an operator at a remote location with the use of cameras, sensors, and additional positioning software. Tele-operation allows operators to further remove themselves from the mining location to control a vehicle from a more protected environment. Semi-automation refers to partially automated control of mining machines. Only some of the functions are automated, and operator intervention is needed. Neverthless, full automation refers to the autonomous control of one or more mining machines. Robotic components manage all critical functions including ignition, steering, transmission, acceleration, braking, and implement control without the need for operator intervention.

As can be understood from the above definitions, each mode of mine automation requires the different mine structure and design, operation size, supports and logistics, human resources, maintenance management and safety disciplines. The failure modes, reliability, efficiency and utilization characteristics are different in various types of automated systems as well. Since the focus of this research is maintenance, so we consider it more in detail. As shown in Figure 1.

Maintenance is a process which needs specific inputs and provides a sort of outputs. In comparison, all inputs in the maintenance of automated machinery are different from those in non-automated. Even the same maintenance operation might result in completely different output in automated mining machinery. Because, the complexity of machinery especially in a harsh environment such as mining sometimes reduces the quality of failure detection and repair actions. 


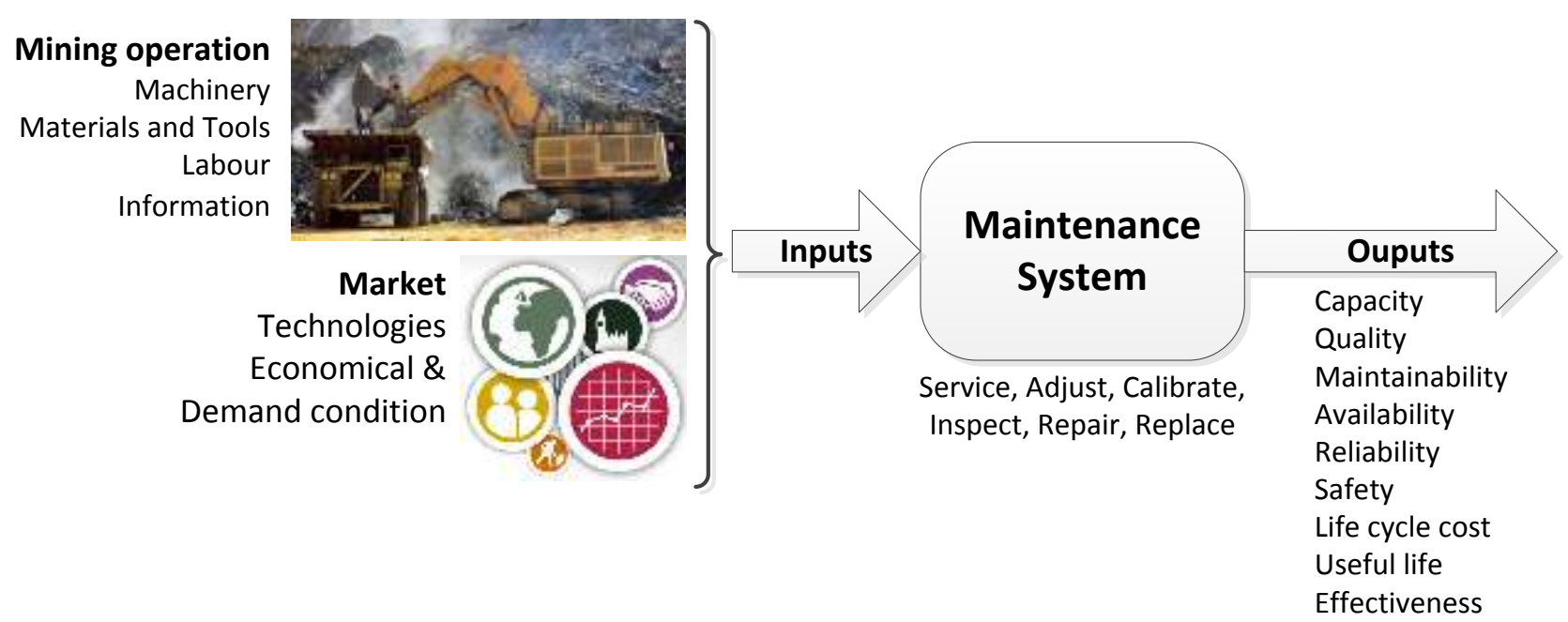

Figure 1. Systemic approach of maintenance in mines

\section{Maintenance challenges in automated mining machinery}

Maintenance plays such an important role in the effectiveness of mine operation. Through short daily inspections, cleaning, lubricating, and making minor adjustments, small problems can be detected and corrected before they become a major problem that can stop the production [3]. Maintenance should help to keep a systems facilities functioning in order to contribute to the company goals. So, maintenance should fulfill requirements of the right CRAMP parameters (Cost, Reliability, Availability, Maintainability, and Productivity) for any automation system. Engineering of such a maintenance system needs a holistic approach for integrating views and evaluations, not only of the systems themselves, but also for their mutual interactions and their interactions with the environment [4, 5].

With the introduction of electronic components such as engine management systems and onboard control and diagnostic systems on mining machines, the potential to optimize the maintenance cycle and increase machine's availability has increased significantly [6]. However new challenges have been raised due to the complexity of automated mining machinery and even from the advanced maintenance technologies themselves. In this part it is aimed to briefly present the main challenges of automated mining machinery. It should be considered that the list of challenges discussed here is not all-inclusive, nor are necessarily common to every mine. But they are thought to represent a mainstream of experiences that have been observed so far.

\section{A. Safety of maintenance crew}

Automation increases the mine operation safety in high and considerable level specially with excluding the operator from hazardous operation area. However, when the machinery fail and needs maintenance, the maintenance crews have to enter in this hazardous area to fix the problem (however, smart system take the maintenance to a picking point when degradation is going on in order to avoid any unexpected stoppages and people coming into hazardous areas). Since all machinery operate automatically, detecting the human is difficult (sometimes even impossible) for machinery and some tele-operators (due to darkness or notclean on-board camera). In addition some software and hardware failures have direct safety consequences. For instance, Bulletins [7] and Sammarco [8] studied the safety issues of programmable electronics (PE) and found that 11 incidents occurred in United States mines during 19952001, with four resulting in fatalities. During the same period, 71 similar incidents occurred in underground coal mines in New South Wales, Australia. Most of the incidents involved sudden start-ups or movements of PE-based mining systems. A study by United Stats Mine Safety and Health Administration (MSHA) on American and Australian longwall equipment reports that $35 \%$ of sudden movements can be traced to four problems: water ingress, software programming errors, sticking or defective solenoid valves, and operator error [9].

\section{B. Big data}

Mining operation consists of a large fleet of machineries which all are distributed in several locations and with different operational configurations. In automated mining systems, a lot of Information and Communication Technologies (ICT) based tools/systems are installed to enable the automation system to work properly and to track and optimize the mine production. These systems are very precise and any interruptions in production are logged with a high level of accuracy. Universally acknowledged key performance indicators such as availability, mean time between failures and mean time to restore can be calculated with ease from this data thus developing asset or fleet level awareness for the management. These systems are production-centric and they can record when an asset has broken down, and details regarding what has happened and where has it happened. This provides a holistic view of automated mining operation, monitoring and improving the performance. However it leads us to capture huge amount of data for further analysis and better understanding shortfalls and areas for improvement in the operations [6]. In this regard, data acquisition, processing and decision making are the core part of maintenance management in automated mining operation.

Over the past 30 years, the level, size and volume of information available for industry has increased 
dramatically. But "big data" are a challenge when we are dealing with continuous data collection using different types of sensors. Using the classical statistical method, it is not possible to obtain a comprehensive understanding of different dimensions of data. In other words, classical methods fail to capture all information; whereas big data analytics are helpful in such situations. Figure 2 presents Big Data issues and elements in maintenance of complex automated mining systems.

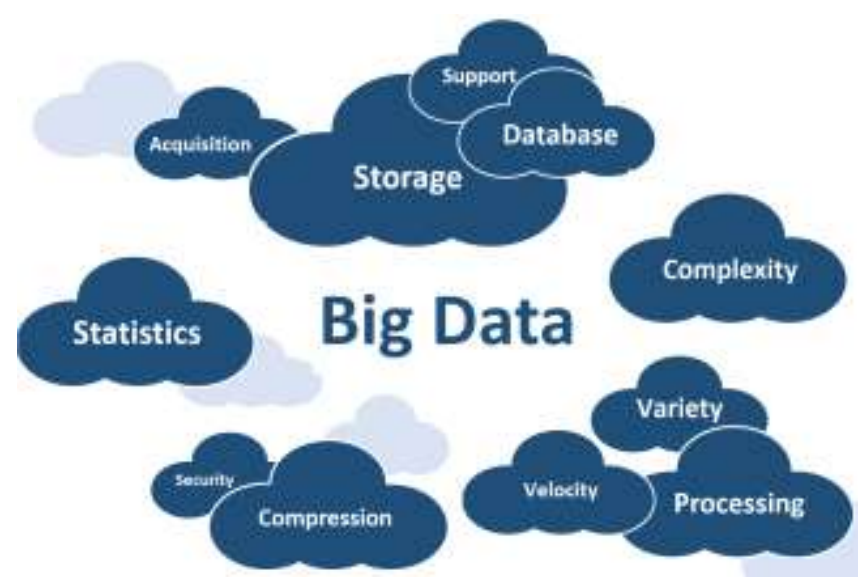

Figure 2. Big data issues and elements in maintenance

\section{Integration of automation system}

The main difference between mining and plant installations is the moving work place in mining as the face advancement and exploitation. It is therefore difficult to install and maintain reliable networks and infrastructure, and makes on-board diagnostics an absolute must, to ensure a high availability, safe and uninterrupted operation of the mining machinery [6]. Mining as a complex production system consists of several subsystems (machinery and process). The integrity of these subsystems critically affects the mine capacity/production and maintenance planning.

In other view, since each of the different manufacturers and suppliers of the systems, devices, and components has their own designs and configurations, so the automated system frequently suffers from a lack of integration. The parts used in one automated system may not match those in another due to the existence of proprietary systems and lack of open platforms and communication gateways which facilitate the bridges among the deployed systems, thereby creating problems that end in system stoppage and downtime. To prevent this, a standard must be defined and made available to all users and manufacturers. Currently, designers often start from scratch when building solutions.

\section{Towards SMART solutions}

During the last 20 years, it has been tried to develop new technologies which enable the mining companies to maintain their assets in the highest possible safety levels, accuracy and lowest costs. Neverthless, still none of advanced maintenance methods have been tested and implemented in automated mining machinery completely. Regarding the three mentioned maintenance challenges in automated mines, any maintenance solution in such systems should provide a comprehensive and deep understanding of automated machinery. This is achieved by building up a strong database of failures and performed maintenance actions as well as efficient performance and condition monitoring systems. Two well-known maintenance solutions which can be helpful in building up a strong database, improving the safety of maintenance, solving the big data problems and enhancing the system integration are: Reliability Centered Maintenance (RCM) and eMaintenance. Therefore, these two concepts are shortly discussed in this part and mainly recommended for implement in automated mining systems.

\section{A. Reliability Centered Maintenance}

Since RCM classifies and simplifies the maintenance tasks, it is one of the most applicable methods to improve the maintenance plans for complex automated systems. The methodology as cost effective one, takes into account the prime objectives of a maintenance program: minimize costs, meet safety and environmental and operational goals. RCM is an engineering framework that enables the definition of a complete maintenance regime. As a discipline, it enables machine stakeholders to monitor, assess, predict and generally understand the operation of their physical assets $[10,11]$. The method starts by identifying the operating context of the machinery and by performing a Failure Mode Effects and Criticality Analysis (FMECA). The second part of the analysis is the application of the "RCM logic", which helps to determine the appropriate maintenance tasks for the identified failure modes in the FMECA. Once this is completed for all elements in the FMECA, the resulting list of maintenance task for all system becomes ready. Figure 3 shows different maintenance strategies in a typical RCM program.

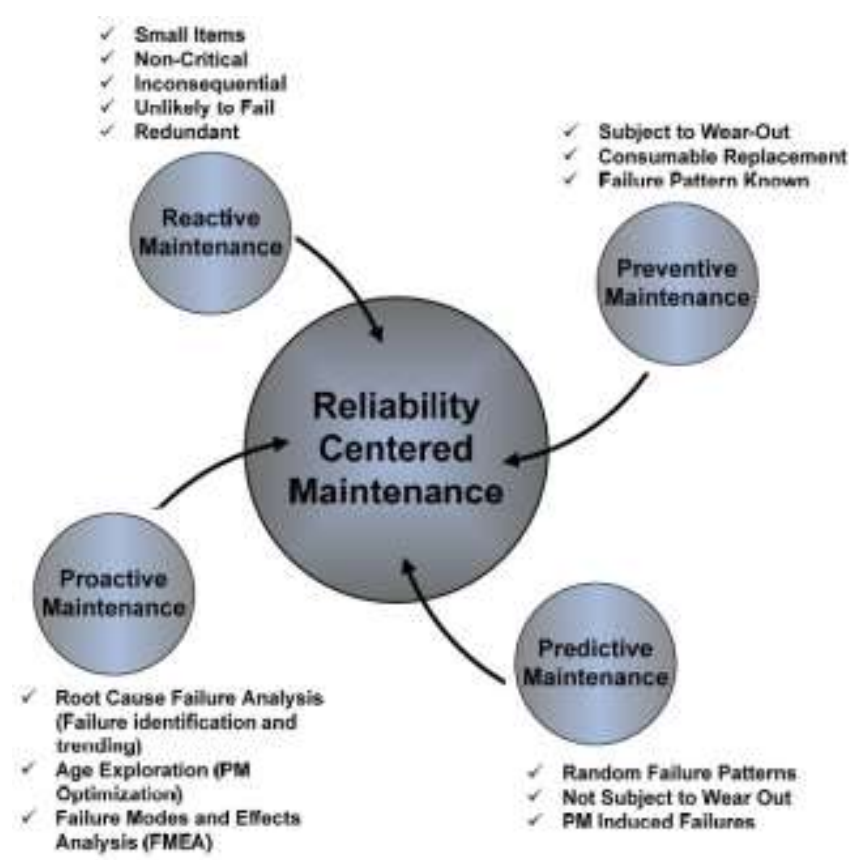

Figure 3. Different maintenance strategies and related tools included in $\mathrm{RCM}$ program [12]

Recently, a new advanced RCM-based technique which is called intelligent RCM (iRCM) has been developed for implementation of RCM in complex systems [13]. In iRCM, in order to improve the efficiency of RCM analysis, casebased reasoning (CBR), as a kind of artificial intelligence 
(AI) technology, is successfully introduced into RCM process. The idea for iRCM is based on the fact that the historical records of RCM analysis on similar items can be referenced and used for the current RCM analysis of a new item. Because many common or similar items may exist in the analyzed equipment, the repeated tasks of RCM analysis can be considerably simplified or avoided by revising the similar cases in conducting RCM analysis.

As explained, iRCM has a good capability to deal with big data and is able to combine the past and real-time data in a reasonable quality. Therefore, it could be an efficient solution for maintenance planning of complex and largescale systems. Accordingly, it is recommended by authors to be implemented in maintenance planning of automated mining machinery.

\section{B. eMaintenance}

As mentioned earlier, the automated mining machinery is supposed to be monitored both from the operation and maintenance point of view. Therefore, huge amount of data is generated in the form of 24/7 (24 hours per day, 7 days per week). Collection, storing, analysis and extracting the decision support through the big data are serious challenges of advanced mining. One of the powerful platforms which can efficiently help the maintenance of automated operation is eMaintenance. The concept of eMaintenance, nowadays maintenance 4.0 , is widespread in the industry and refers to the integration of the ICT within the maintenance strategy and/or plan to face with new needs emerging from innovate ways for supporting production. eMaintenance enables the mining companies to establish the intelligent maintenance systems to predict and forecast machinery performance so "near-zero breakdown" status is achieved. Operational data usually comes from three sources: sensors (mounted on the machines), the entire enterprise system (including quality data, past history and trending) and external context (social, economic, geographical, etc.). By looking at data from these sources (current and historical), it can predict the future performance. It also provides a powerful structure to get the highest possible integration in automation systems. Figure 4 presents the main structure and elements of eMaintenance in automated mining operation.

\section{v. Conclusion}

Presented discussions in this paper and reviewed literature, show that each mode of mine automation has specific failure modes, reliability, efficiency and utilization characteristics. Therefore, in order to design an effective maintenance system for these kinds of mining machinery, all structural and operational aspects should be considered in a proper way. Three main challenges in the maintenance of automated mining machinery are: safety of maintenance crew, big data and integration of automation subsystems. Integration and big data are new issues, but safety is an old and much regulated challenge in maintenance of mining machinery.

In order to overcome the above mentioned challenges, two main advanced maintenance solutions are recommended to be implemented in automated mines: RCM and eMaintenance. RCM which has been originally developed in the aviation industry has great capability to build up a logical structure for maintenance management and improvement in mines. The intelligent RCM (iRCM) is strongly recommended for implementation. It provides a great integration among the past and real-time big data and enables us to understand the machinery failure is and efficient and cost effective way. eMaintence as a tool for smart and autonomous maintenance could have a notable effects on maintenance and support of automated mining machinery in a safe manner.

\section{Acknowledgment}

This work is based upon work supported by the Sweden's Innovation Agency (Vinnova) under Grant No. 201501348 .
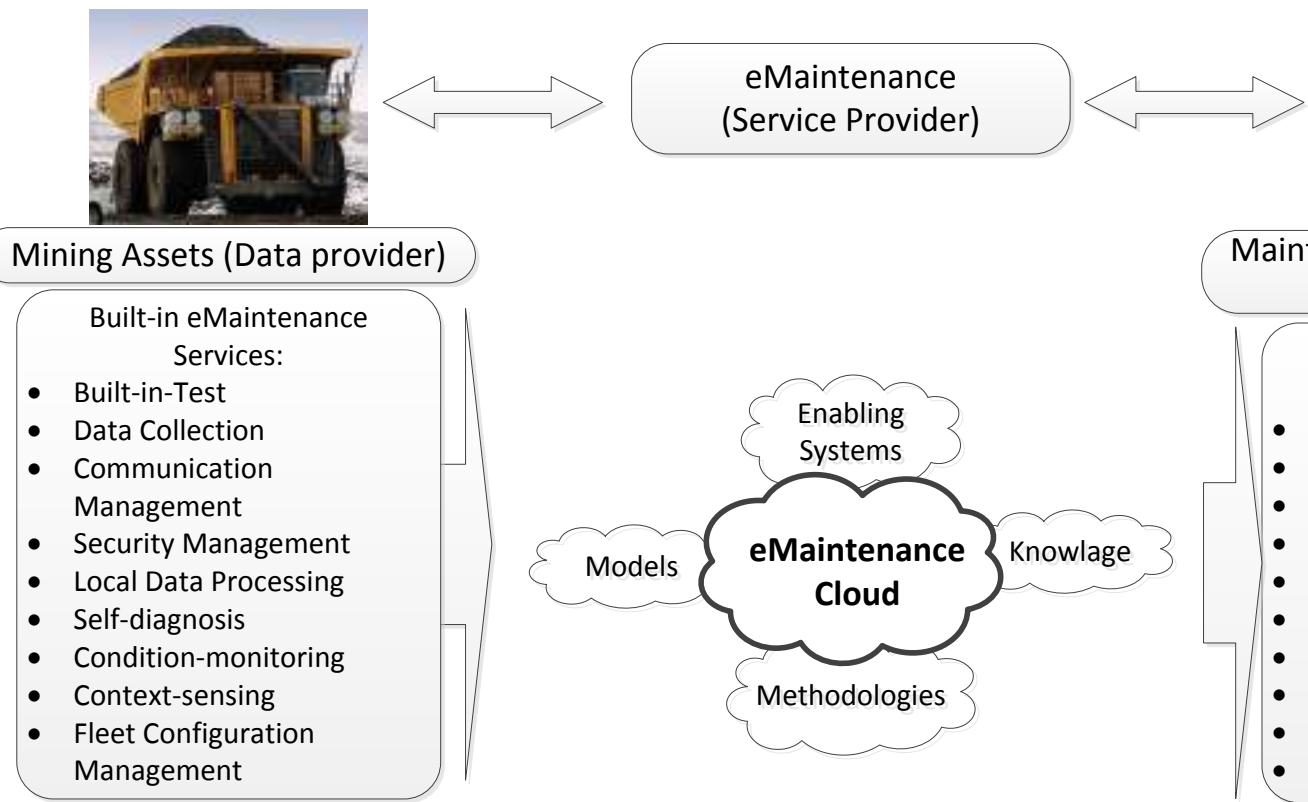

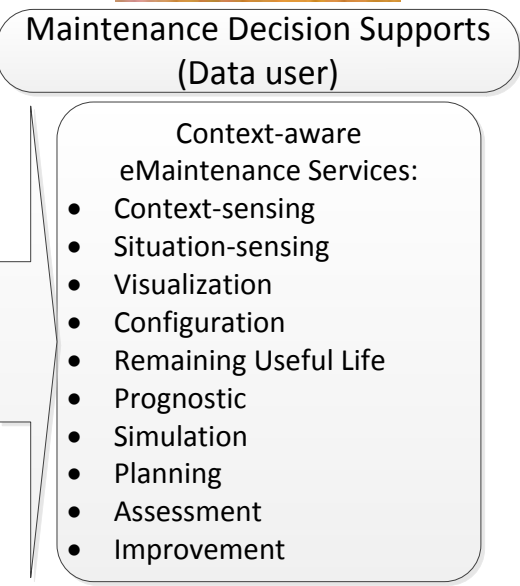

Figure 4. Structure and elements of eMaintenance in automated mining operation

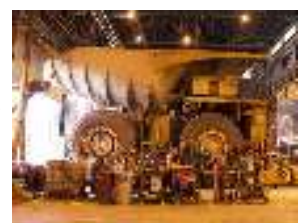

ce Decision Supports

Context-aware

eMaintenance Services:

- Context-sensing

- Situation-sensing

- Visualization

- Configuration

- Remaining Useful Life

- Prognostic

- Simulation

- Planning

- Assessment

Improvement 


\section{References}

1. P. Darling, SME mining engineering handbook, Vol. 1, SME, (2011).

2. S.Y. Nof, Springer handbook of automation, Springer Science \& Business Media, (2009).

3. S. Krar, "The importance of maintenance (changing from a fail and fix approach to predict and prevent approach)", available in: http://www.automationmag. com

4. A. Gustafson, H. Schunnesson, D. Galar, and U. Kumar, "Production and maintenance performance analysis: manual versus semi-automatic LHDs", Journal of Quality in Maintenance Engineering 19 (2013), pp. 7488.

5. H. Erbe, IFAC Professional Brief Technologies for Cost Effective Automation in Manufacturing (Low Cost Automation), available in: http: //www.zmms.tuberlin.de/LCA

6. G. Morel, M. Suhner, B. Iung, J. B. Léger, "Maintenance holistic framework for optimizing the cost/availability compromise of manufacturing systems." In: Proceedings of the sixth IFAC symposium on cost oriented automation. Survey Paper, Berlin, Germany, October, (2001).

7. A. Marek, S.C. Thorley, H. Haubmann, "The age of intelligence. online diagnostic and automated maintenance planning", 5th Platinum Conference 2012, The Southern African Institute of Mining and Metallurgy, Sun City, South Africa, 18-20 September, (2012).

8. F.A. Bulletins, Fatal Grams and Fatal Investigation Reports, Mine Safety and Health Administration (MSHA), Washington, DC (2001).

9. J. J. Sammarco, "Addressing the safety of programmable electronic mining systems: lessons learned", Industry Applications Conference, 2002. 37th IAS Annual Meeting. Conference Record of the, (2002).

10. B. S. Dhillon, "Mining equipment reliability, maintainability, and safety", Springer Science \& Business Media, (2008).

11. A. M. Smith and G. R. Hinchcliffe, "RCM- Gateway to World Class Maintenance Hardcover", Elsevier, Butterworth-Heinemann, (2004), p.360.

12. J. H. Williams, "Condition-Based maintenance and machine diagnostics", Kluwer Academic Publishers, Londen UK., (1992), p.187.

13. T. Jackson, "Developing and Implementing RCM for a Limited Staffed Facility", Cohesive Information Solutions, Colorida, USA, available online: www.reliabilityweb.com

14. Z. Cheng, X. Jiab, P. Gaoa, S. Wua, J. Wang, "A framework for intelligent reliability centered maintenance analysis", Reliability Engineering and System Safety 93 (2008), pp. 784-792.

15. C. Resteanu, I. Vaduva, M. Andreica, "Monte Carlo Simulation for Reliability Centered Maintenance Management", 6th International Conference, LSSC2007 Sozopol, Bulgarien, June 5-9, 2007.
About Authors:

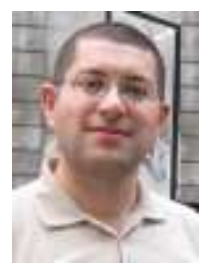

Seyed Hadi Hoseinie is an Assistant Professor in Division of Operation and Maintenance Engineering at Luleå University of Technology, Sweden. His research interests are; mining machinery, reliability centered maintenance, mechanical excavation and mine automation. He has published more than 65 articles in international journals conferences proceeding. He currently holds one patent too.

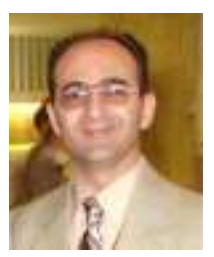

Behzad Ghodrati is Associate Professor of Maintenance and Reliability Engineering at Lulea University of Technology. He obtained his PhD degree on "Spare parts planning" from Lulea University of Technology and he was awarded the Postdoctoral Research Fellowship from University of Toronto in 2008. He has published more than 60 papers in international journals and conference proceedings and a book chapter.

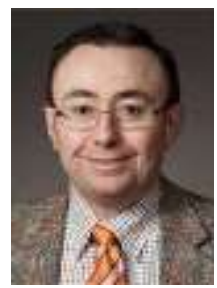

Diego Galar is Professor of Condition Monitoring at Lulea University of Technology. He has obtained his $\mathrm{PhD}$ in Industrial Engineering and Telecommunication Engineering from the University of Zaragoza. He has served as professor at several universities including the University of Saragossa or the European University of Madrid, Instituto Politecnico de Braganca IPB, ANANTASA technical director, director of academic innovation and director of international relationship at university. $\mathrm{He}$ has published many articles in international journals and conference proceedings. 